\title{
Dermatose responsiva à biotina em cão
}

\author{
Dermatosis responsive to Biotin in a dog
}

\begin{abstract}
Sandra Prudente Nogueira' ${ }^{I}$ Márcio Antonio Brunetto ${ }^{I}$ Juliana Toloi Jeremias ${ }^{\mathrm{I}}$ Márcia de Oliveira Sampaio Gomes ${ }^{\mathrm{I}}$ Eliana Teshima ${ }^{\mathrm{I}}$ Aulus Cavalieri Carciofi ${ }^{\mathrm{II}}$
\end{abstract}

\section{- NOTA -}

\section{RESUMO}

Os transtornos da pele e dos pelos são parte importante na prática clínica de pequenos animais. Numerosos fatores nutricionais afetam a homeostase, a qualidade e o aspecto da pelagem. As vitaminas do complexo B incluem compostos hidrossolúveis necessários como coenzimas em diversas funções celulares envolvidas no metabolismo energético e na síntese tecidual. A biotina, em especial, é necessária nas reações de carboxilação, participando da síntese de ácidos graxos, aminoácidos e purinas pelo tecido epitelial. Uma cadela com quadro de cistite recorrente e tumor venéreo transmissível foi tratada com antibioticoterapia prolongada $e$ quimioterapia. Após alguns meses de tratamento, foram observadas lesões no plano nasal e nos coxins plantar e palmar, caracterizadas por hiperceratose, espessamento, fissuras, sangramento e inflamação. $O$ paciente recebeu suplementação de $15 \mathrm{mg}$ de biotina por via oral (equivalente a $1,4 \mathrm{mg} \mathrm{kg}^{-1}$ de peso corporal), uma vez por dia, durante 60 dias, havendo importante regressão das lesões. Sugere-se que, sob antibioticoterapia e doença, a síntese intestinal de biotina possa não ter sido suficiente, sendo necessária sua suplementação.

Palavras-chave: pele, deficiência nutricional, vitaminas do complexo B, cão.

\section{ABSTRACT}

Skin and hair diseases are an important part in small animal's clinical practice. Many nutritional factors can affect the quality and the aspect of the coat. B complex vitamins are water-soluble compounds used as coenzymes in several cellular functions that are involved in energy metabolism and tissue synthesis. Biotin, in particular, is necessary for carboxylation reactions, fatty acids synthesis, and incorporation of essential amino acids and purines in the epithelial tissue. A female canine with recurrent cystitis and sticker tumor was treated chemotherapy and prolonged antibiotic therapy. After a few months of medications, lesions were observed in nasal plan and palmar and plantar pads, characterized by hyperkeratosis, skin thickness, bleeding fissures, and inflammation. The patient was treated with $15 \mathrm{mg}$ of oral biotin supplementation (1.4mg kg-1 of body weight) once a day, for 60 days, with significant regression of skin lesions at the end of this period. These findings suggest that in certain diseases and particularly in prolonged antibiotics therapy, intestinal biotin synthesis may not be adequate, demanding oral supplementation.

Key words: skin, nutritional deficiency, complex B vitamins, canine.

Os transtornos da pele e dos pelos são parte importante na prática clínica de pequenos animais. Numerosos fatores nutricionais afetam a homeostase, a qualidade e o aspecto da pelagem desses animais (ROUDEBUSH et al., 2000). As vitaminas do complexo $\mathrm{B}$ incluem compostos hidrossolúveis utilizados como coenzimas em diversas funções celulares envolvidas no metabolismo energético e na síntese de tecidos (PRELAUD \& HARVEY, 2006). A biotina é necessária nas reações de carboxilação e essencial ao metabolismo de carboidratos, proteínas e gorduras, participando da

IPrograma de Pós-graduação em Medicina Veterinária, área de concentração Clínica Médica, Faculdade de Ciências Agrárias e Veterinárias (FCAV), Universidade Estadual Paulista (UNESP), Campus de Jaboticabal, Jaboticabal, SP, Brasil.

${ }^{\text {II }}$ Departamento de Clínica e Cirurgia Veterinária, FCAV, UNESP. Via de Acesso Prof. Paulo Donato Castelane, s/n, 14884-900. Campus de Jaboticabal, Jaboticabal, SP, Brasil. E-mail: aulus.carciofi@gmail.com.br. Autor para correspondência. 
síntese de ácidos graxos, aminoácidos, purinas e ácido nucleico. Apesar de ser encontrada em diversos tipos de alimentos, sua biodisponibilidade é bastante variável (CASE et al., 1998) e sua concentração mais baixa, quando comparada à de outras vitaminas hidrossolúveis (NRC, 2006). Fontes dessa vitamina incluem o fígado, os rins, a gema do ovo, a soja e as leveduras. Os cereais, as carnes e seus derivados, principais ingredientes das rações para cães, são pobres em biotina (McDOWELL, 1989).

As bactérias intestinais sintetizam biotina, e acredita-se que boa parte, senão toda a demanda, pode ser atendida por esta via. BOWMAN \& ROSENBERG (1987) observaram em ratos que, embora o transporte de biotina ocorra principalmente no intestino delgado, a absorção no colón proximal é significativa. Algumas drogas, como as sulfas, sob determinadas circunstâncias, podem induzir deficiência de biotina por redução de sua produção intestinal (McDOWELL, 1989). Os sinais mais importantes da deficiência de biotina ocorrem no tegumento, apesar de serem relatados sinais inespecíficos, como anorexia, perda de peso e mesmo quadros neurológicos.

Não existem estudos que descrevem adequadamente os sintomas da deficiência de biotina em cães; relatos antigos descrevem hiperceratose em epiderme e folículos, sem alterações evidentes em pelos (NRC, 2006). Livros textos mais recentes a associam à seborreia seca e descamativa, à alopecia, a caspas e à pelagem áspera, com lesões especialmente na face, ao redor dos olhos, e formação de crostas nos casos severos (SCOTT et al., 2001; PRELAUD \& HARVEY, 2006). No entanto, esses sinais não foram verificados mediante indução experimental ou em condições que pudessem vir a ser atribuídos exclusivamente à deficiência de biotina, podendo ser resultantes da deficiência associada de várias vitaminas. Sua deficiência é considerada de ocorrência rara em cães, estando pobremente documentada (NRC, 2006). Em situações de doença prolongada e uso contínuo de antibióticos que reduzem a população bacteriana intestinal, acredita-se que a demanda dietética desse nutriente possa estar aumentada, podendo levar à ocorrência de deficiência (BALNAVE, 1977; WILLS \& SIMPSON, 1995; PRELAUD \& HARVEY, 2006). Em relação a sua toxicidade, não há relatos em cães, já que sua excreção via urinária é eficiente e os níveis tolerados bastante elevados (NRC, 2006).

Uma cadela de três anos, sem raça definida e peso corporal de $21 \mathrm{~kg}$ foi atendida no Hospital Veterinário “Governador Laudo Natel” - FCAV/Unesp, Campus de Jaboticabal, São Paulo (SP), apresentando aumento de volume em vagina. No exame físico e nos exames complementares, foram verificadas mucosas hipocoradas, anemia (hematócrito 32,8\%) e cistite, esta evidenciada por meio de urinálise, e tumor venéreo transmissível, diagnosticado por citologia aspirativa por agulha fina. A paciente foi medicada com enrofloxacina ${ }^{\mathrm{a}}\left(5 \mathrm{mg} \mathrm{kg}^{-1}\right.$ duas vezes ao dia, durante 15 dias, sendo repetido o tratamento após quatro semanas, por mais 21 dias, em decorrência da persistência da cistite) e quimioterápico sulfato de vincristinab $(0,5 \mathrm{mg}$ $\mathrm{m}^{2}$ em seis aplicações, uma por semana). Após quatro meses do início do tratamento, o animal apresentou melhora do quadro clínico e remissão completa do tumor venéreo transmissível, porém houve recidiva da cistite, sendo necessária a substituição do antibiótico por cloranfenicol $^{\text {c }}$ (40 $\mathrm{mg} \mathrm{kg}^{-1}$ três vezes ao dia, durante 15 dias). Em todo o período, a cadela foi alimentada com dieta comercial de boa qualidade, em quantidade suficiente para manutenção do peso corporal.

Após seis meses do início do tratamento, o animal passou a apresentar lesões no plano nasal e nos coxins plantares (Figuras 1A e 1B) e palmares, caracterizadas por hiperceratose, espessamento, fissuras, sangramento e inflamação, que dificultavam sua locomoção. Além disso, os pelos apresentavam-se ressecados, opacos e quebradiços. Frente a esse quadro, foi instituída suplementação com 15mg de biotina $^{\mathrm{d}}$ por via oral, uma vez por dia, havendo melhora dos sinais dermatológicos com regressão das lesões após 60 dias (Figuras 1C e 1D). Acompanhando a melhora dos coxins e da trufa nasal, os pelos do animal também melhoraram de aspecto, sendo observado pelame liso, brilhante e uniforme. Em função da remissão dos sinais dermatológicos, optou-se por suspender a suplementação com biotina. Passados 40 dias, o animal voltou a apresentar o mesmo quadro clínico. Procedeuse então à coleta de fragmento do coxim plantar por biópsia com punch de $0,4 \mathrm{~cm}$, que foi fixado em solução tamponada de formol a $10 \%$ e encaminhado para exame histopatológico. O fragmento foi cortado ao meio, incluído em parafina, seccionado a $5 \mu \mathrm{m}$ e corado pelas técnicas de hematoxilina e eosina e ácido periódico de Schiff (PAS). A suplementação com biotina foi retomada, na mesma posologia descrita anteriormente.

Após 90 dias de suplementação, o paciente foi reavaliado e foi observada nova melhora dos sinais cutâneos, quando uma segunda biópsia foi realizada. Na biópsia inicial, foram constatadas acantose moderada e ortoceratose lamelar compacta e severa, com fissura da camada córnea, e infiltrado de neutrófilos na epiderme, sendo diagnosticada dermatite acompanhada de hiperqueratose epidermal intensa. $\mathrm{Na}$ segunda biópsia, foi verificada atenuação das alterações histopatológicas, que revelaram discreta 


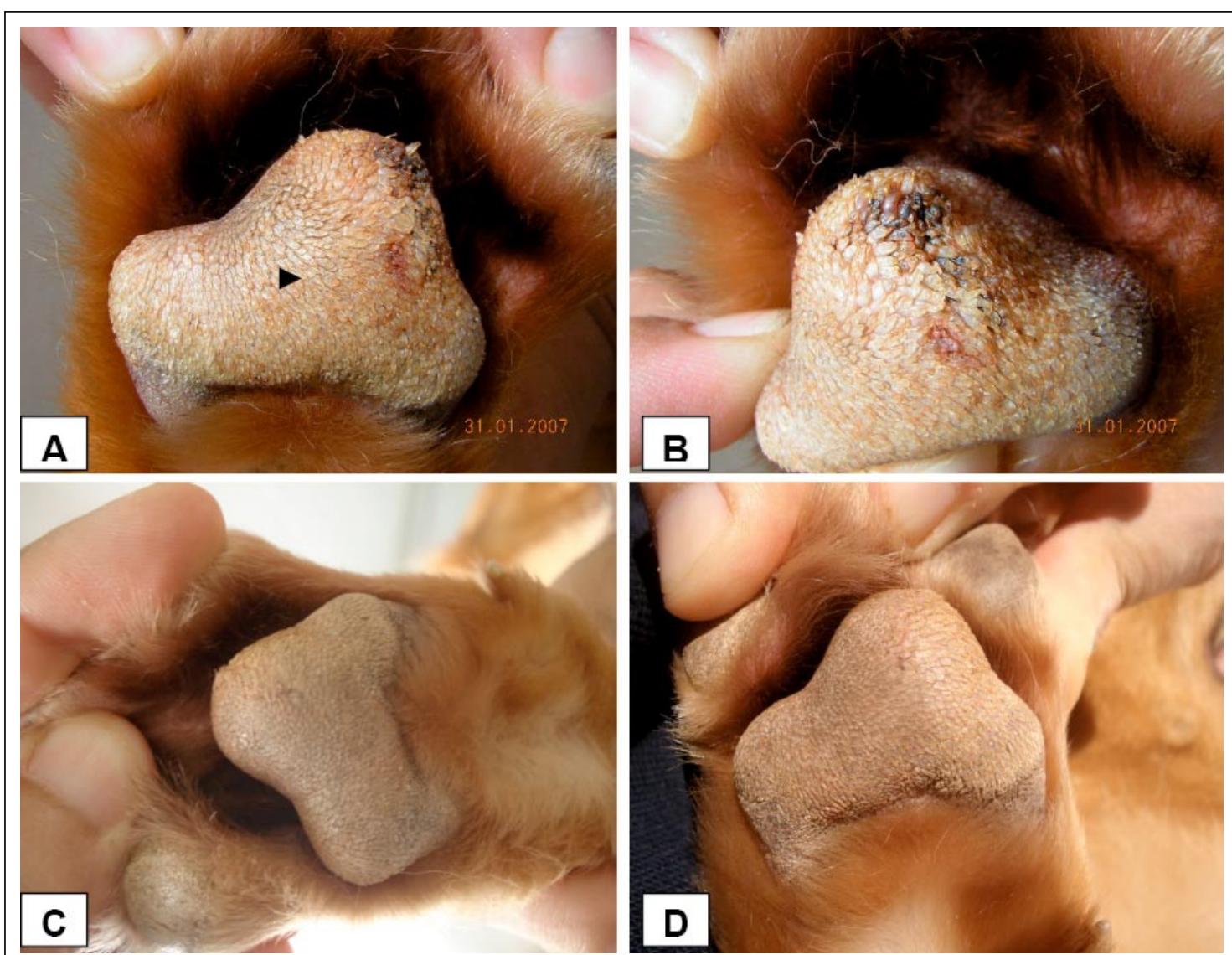

Figura 1 - A e B - coxim plantar de cão antes da suplementação com biotina. Notar a hiperceratose vilosa. C e D - coxim plantar de cão após 70 dias de suplementação com $15 \mathrm{mg} \mathrm{dia}^{-1}$ de biotina. Notar a melhora do quadro hiperceratótico.

acantose e ortoceratose compacta, diagnosticando-se hiperceratose epidermal leve a moderada.

Considerando que a dieta do animal não mudou ao longo do estudo e que nenhuma medicação para a pele foi instituída, pode-se atribuir à terapia com biotina a importante melhora clínica evidenciada nas duas vezes da suplementação vitamínica. Como as vitaminas hidrossolúveis não são estocadas no organismo, suas necessidades devem ser constantemente supridas a partir da combinação de fontes dietéticas e da biossíntese pela microbiota intestinal (McDOWELL, 1989). Em relação a sua presença na dieta, como já evidenciado, a biotina é pobremente distribuída nos ingredientes comumente empregados na fabricação de alimentos para cães (NRC, 2006). Além disso, em razão de sua síntese intestinal ser considerada suficiente, não há recomendações para sua inclusão nos alimentos para essa espécie (NRC, 2006), estando sua adição ou não condicionada aos princípios nutricionais adotados pela empresa.

No presente relato, a resposta do animal à suplementação com biotina poderia ser explicada pelas seguintes hipóteses: o paciente apresentava quadro infeccioso crônico (cistite) associado à presença de neoplasia, situação estressante prolongada que poderia ter aumentado a demanda pelo nutriente; e a antibioticoterapia prolongada para tratamento da cistite poderia ter alterado a microbiota intestinal e consequentemente a síntese de biotina (NRC, 2006).

O aumento da demanda do nutriente em cães com infecções ou outras enfermidades relacionadas é defendido por alguns autores, predispondo o paciente a deficiências nutricionais (REYES \& GONZÁLES, 2002). O uso de antibioticoterapia oral prolongada, anorexia ou aumento da perda de água em condições de poliúria ou enterites também pode resultar em deficiência, tornando recomendável a suplementação (PRELAUD \& HARVEY, 2006), especialmente quando ocorrem dermatoses e desordens de ceratinização (WATSON, 1998). No presente caso, não houve poliúria, polidipsia, sinais gastrintestinais ou anorexia, reforçando a hipótese de baixa síntese intestinal decorrente da antibióticoterapia. 
A presente nota apresenta caso clínico de alteração cutânea que respondeu à suplementação oral com biotina, em paciente sob antibioticoterapia e com doença infecciosa e neoplásica concomitante. Poucos relatos e estudos existem sobre a necessidade dessa vitamina para cães. Esses resultados sugerem que esta possa ser empregada como recurso terapêutico em desordens de ceratinização, especialmente quando localizadas em coxins, bem como deva ser suplementada nos alimentos industrializados, especialmente naqueles destinados a pacientes enfermos ou com alterações dermatológicas.

\section{AGRADECIMENTOS}

À Mogiana Alimentos S.A. (Guabi), pelo suporte técnico e financeiro; ao Serviço de Nutrição Clínica de Cães e Gatos do Hospital Veterinario da FCAV/UNESP, Jaboticabal.

\section{FONTES DE AQUISIÇÃO}

a - Flotril 50mg, Schering Plough, São Paulo, SP

b - Tecnocris, Zodiac, Pindamonhangaba, SP

c - Quemicetina 500mg, Neo Química, Anápolis, GO

d - Biotina - vitamina H, Sintofarm, Guastalla, Itália

\section{REFERÊNCIAS}

BALNAVE, D. Clinical symptoms of biotin deficiency in animals. American Journal of Clinical Nutrition, v.30, p.1408-1413, 1977. Disponível em: <http://www.ajcn.org/cgi/ reprint/30/9/1408>. Acesso em: 15 nov. 2008.

BOWMAN, B.B; ROSENBERG, I. Biotin absorption by the distal rat intestine. Journal of Nutrition, v.117, p.2121-
2126, 1987. Disponível em: <http://jn.nutrition.org/cgi/reprint/ 117/12/2121>. Acesso em: 31 out. 2008.

CASE, L.P. et al. Nutrição canina e felina: Manual para profissionais. Madrid: Harcourt Brace, 1998. 424p.

McDOWELL, L.R. Vitamins in animal nutrition. San Diego: Academic, 1989. 486p.

NATIONAL RESEARCH COUNCIL. Nutrient requirements of dogs and cats. Washington: The National Academy, 2006. 424p.

PRELAUD, P.; HARVEY, R. Nutritional dermatoses and the contribution of dietetics in dermatology. In: PIBOT, P. et al. Encyclopedia of canine clinical nutrition. Paris: Aniwa SAS, 2006. p.58-91.

REYES, E.C.G.; GONZÁLEZ, N.M. Deficiencia de biotinidase. Bioquimica, v.27, p.80-86, 2002. Disponível em: <http:// www.medigraphic.com/espanol/e-htms/e-bioquimia/e-bq2002/ebq02-3/em-bq023d.htm>. Acesso em: 19 nov. 2008.

ROUDEBUSH, P. et al. Trastornos de la piel y el pelo. In: HAND, M.S. et al. Nutrición clínica en pequeños animales. 4.ed. Bogotá: Panamericana, 2000. p.537-560.

SCOTT, D.W. et al. Muller \& Kirk - Dermatologia dos pequenos animais. 6.ed. Philadelphia: Saunders, 2001. 1528p.

WATSON, T.D.G. Diet and skin disease in dogs and cats. Journal of Nutrition, v.128, p.2783S-2789S, 1998 Disponível em: <http://jn.nutrition.org/cgi/reprint/128/12/ 2783S>. Acesso em: 02 nov. 2008.

WILLS, J.M.; SIMPSON, K.W. Enfermidade de la piel. In WILLS, J.M. El Libro de Whaltam de nutricion clínica del perro y el gato. Zaragoza: Acribia, 1995. p.489-510. 